\title{
PERSEPSI WISATAWAN LOKAL TERHADAP CITRA KOTAGEDE SEBAGAI DESTINASI WISATA
}

\author{
Nina Noviastuti \\ NIDN. 0509117102 \\ email : nina@akparda.ac.id
}

\section{Asmarani Februandari \\ NIDN.0514027701}

email : asmarani@akparda.ac.id

Dosen AKPARDA Yogyakarta

\begin{abstract}
Kotagede is one of heritage area in Yogyakarta that has many historical value and plays an important role for the existence of Yogyakarta nowadays. As a former capital of Mataram Islam Kingdom, this area has several historical and archeological sites, such as royal cemetery complex, the ruin of the fort, and other relics. Kotagede also has 170 heritage buildings that has been built around 1700's until 1930's. Kotagede also known from its silver industry. Based on Kotagede's potentials, the government of Yogyakarta enacts this area as heritage area and becoming one of tourism destination in Yogyakarta. But the development of Kota Gede as tourism destination is still not optimal. Nowadays, Kotagede is more famous as silver industry area than as tourist destination. This research aims at determining destination image of Kotagede as tourism destination. This research use qualitative and quantitative method. The result showed the perception of local tourist on Kotagede's destination image.
\end{abstract}

Keywords: destination image, brand positioning, Kotagede

\section{PENDAHLULAN}

Citra (image) merupakan unsur penting bagi sebuah destinasipariwisata. Hal ini disebabkan oleh karena citra adalah representasi(wakil) dari cerminan/gambaran kondisi dari unsur-unsur yang dimilikidalam destinasi tersebut pada kurun waktu yang relatif cukup lama.Oleh karena itu wisatawan barangkali menggunakan citra destinasi wisata sebagai panduan yang akan mewakili dalam proses pengambilankeputusan, apakah akan berkunjung ke suatu destinasi atau tidak.

Yogyakarta, sebagai salah satu kota tujuan wisata di Indonesia mempunyai banyak sekali potensi wisata, salah satunya Kotagede. Sebagai bekas ibukota kerajaan Mataram, Kotagede banyak menyimpan peninggalan dari kerajaan tersebut yang berupa makam, benteng, dan artefak lainnya seperti Watu Gilang dan Watu Cantheng. Selain itu, Kotagede jugamenyimpan sekitar 170 bangunan kuno yang didirikan pada tahun 1700 hingga1930. Kotagede juga telah ditetapkan oleh pemerintah sebagai kawasan cagar budaya dan telah menjadi salah satu destinasi wisata di Yogyakarta. Namun saat ini Kotagede lebih dikenal sebagai pusat kerajinan perak bahkan banyak orang yang menjuluki Kotagede sebagai "Kota Perak" (ensiklo.com/2014). Meski memiliki potensi yang cukup besar namun agaknya Kotagede sebagai sebuah destinasi wisata masih kurang dikenal terutama bila dibandingkan dengan Kraton, Candi Prambanan, Malioboro, maupun jajaran pantai indah di Kabupaten Gunung Kidul. Sebuah harian umum menyatakan bahwa persoalan sebenarnya lebih pada upaya pengenalan Kota Gede di Kota Yogyakarta sendiri, termasuk 
pembangunan citra Kotagede secara terusmenerus sehingga mampu menjadi simbol pariwisata DIY (http://www. pelita.or.id/baca.php?id=47101).

Berdasarkan paparan diatas, penelitian ini bertujuan untuk mengetahui bagaimana persepsi wisatawan domestik terhadap citra dan posisioning Kotagede sebagai destinasi pariwisata. Sehingga nantinya dapat disusun suatu arahan kebijakan perencanaan dan pengembangan Kotagede sebagai sebuah destinasi pariwisata.

Potensi Kawasan Kotagede yang cukup besar membuat pemerintah setempat menetapkan Kawasan Kotagede sebagai salah satu destinasi wisata di Yogyakarta. Namun, masih banyak wisatawan yang kurang mengenal Kotagede sehinga membuat Kotagede menjadi kurang dikenal terutama apabila dibandingkan dengan beberapa destinasi wisata favorit di Yogyakara seperti Kraton, Candi Prambanan, Malioboro, dan pantai.

Bertolak dari kondisi tersebut, penelitian ini mencoba mengetahui bagaimanakah persepsi wisatawan domestik terhadap citra Kotagede sebagai sebuah destinasi pariwisatan dan memetakan positioning Kotagede.

\section{LITERATURE REVIEW}

\section{Destinasi Wisata}

Menurut Cooper et.al (1998) destinasi pariwisata merupakan perpaduan atau citra/brand dari keseluruhan komponen produk, layanan dan pengalaman kunjungan wisata yang dikembangkan dan disediakan di suatu kawasandengan unsur kelokalannya. Suatu destinasi memiliki beberapa nsure yang saling terkait. Menurut Cooper et.al (1998) terdapat 6 (enam) unsur pembentuk suatu destinasi wisata, yaitu:

1. Atraksi (attraction) yang meliputi alam, budaya, nsurete, dan event.
2. Amenitas (amenity), meliputi fasilitas penunjang wisata, yaitu: akomodasi, rumah makan, retail, kios cendera mata, biroperjalanan, dan money changer.

3. Aksesibilitas, mencakup sistem transportasi yang meliputi jalur transportasi, fasilitas pelabuhan, bandara, terminal, dan moda transportasi (bis, kereta api, pesawat).

4. Fasilitas pendukung (nsurete), yaitu fasilitas-fasilitas pendukung yang diperlukan oleh wisatawan seperti bank, dan rumah sakit.

5. Aktivitas, meliputi seluruh kegiatan yang dapat dilakukan oleh wisatawan pada destinasi tersebut

6. Paket wisata, meliputi paket-paket perjalanan wisata yang diatur dan diselenggarakan oleh biro perjalanan wisata.

\section{Citra Destinasi}

Untuk mengevaluasi apakah destinasi tersebut akan dikunjungi atau tidak wisatawan menggunakan citra destinasi atau image destinasi tersebut untuk mengambil keputusan (Andreassen dan Lindestad, 1998). Citra yang ada dalam benak wisatawan tidak selamanya selaras dengan kondisi destinasi sesungguhnya. Jadi, citra destinasi memiliki potensi dalam mempengaruhi kompetitif tidaknya destinasi (LeBlanc dan Nguyen, 1996). Citra atau image terbentuk berdasarkan persepsi dari wisatawan terhadap unsur-unsur produk wisata yang terdapat pada sebuah destinasi. Citra atau image memegang peranan penting dibandingkan dengan sumber daya pariwisata yang kasat mata. Menurut Pearce (1988),

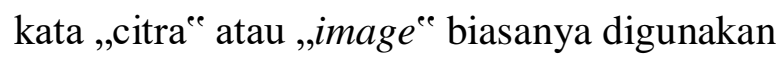
untuk menjelaskan keseluruhan gambar atau stereotip dari suatu destinasi. Sehingga dapat dikatakan suatu citra destinasi terdiri dari 
nsurete based component yaitu nsure-unsur dari suatu destinasi dan holistic component yang merupakan impresi/gambaran destinasi tersebut secara keseluruhan. Citra destinasi juga dapat terdiri darisesuatu yang bersifat umum hingga sesuatu yang bersifat unik (Echtner \& Ritchie, 2003).

\section{Peran Persepsi terhadap Pemilihan Destinasi Wisata}

Dalam dunia pariwisata, persepsi calon wisatawan terhadap suatudestinasi terbentuk berdasarkan stimulus yang didapatnya melalui penginderaan terhadap objek, peristiwa yang berhubungan dengandestinasi dimaksud, baik secara langsung maupun tidak langsung. Pemahaman dan pemaknaan calon wisatawan terhadap suatu destinasibisa saja salah atau berbeda dengan realitas objektif di lapangan. Pilihanuntuk mengunjungi suatu daerah tujuan wisata dipengaruhi oleh persepsiyang terbangun dalam pikiran wisatawan bahwa destinasi yang dipilih tersebut akan mampu memenuhi atau memuaskan kebutuhan yang dirasakannya.

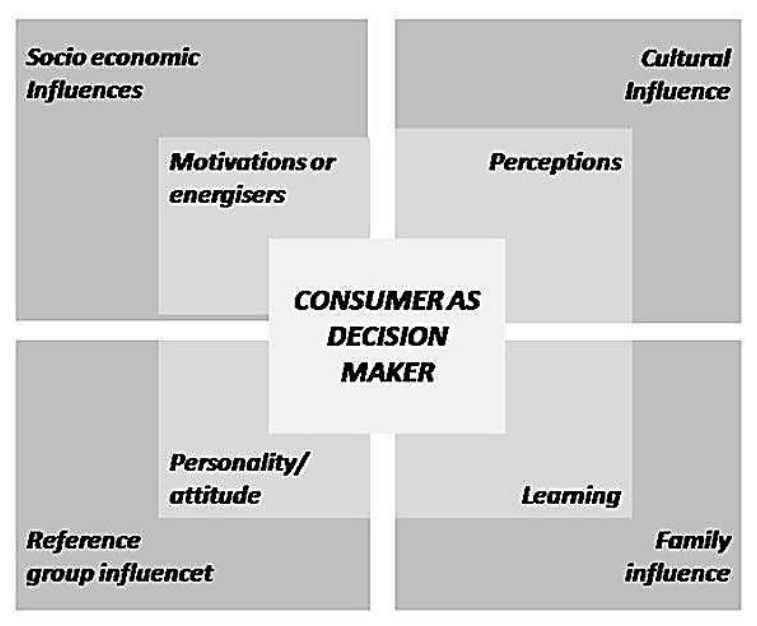

Gambar 1. Kerangka Keputusan Konsumen Sumber: Cooper, Fletcher, Gilbert, Shepherd, dan Wanhill (1998)

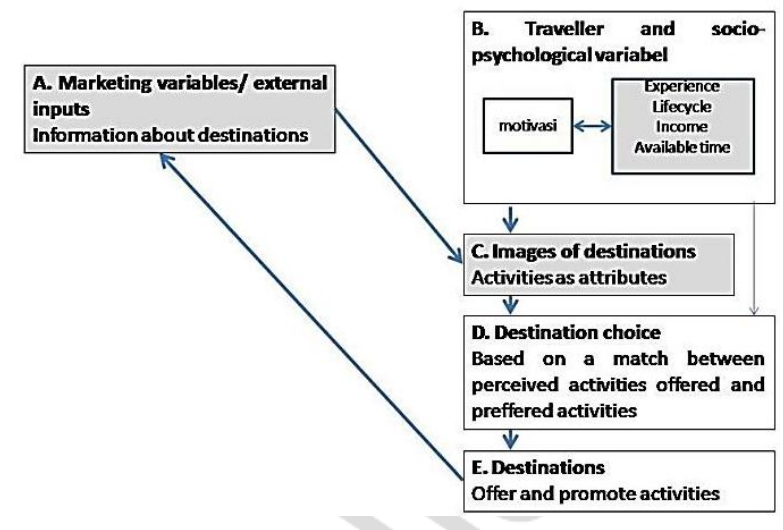

Gambar 2. Pemilihan Destinasi berdasarkan Moscado Sumber: Cooper, Fletchere et.al (1998)

\section{Positioning}

Positioning merupakan suatu konsep untuk menempatkan produk-produk yang terdapat di pasar berdasarkan persepsi dan preferensi konsumen atas suatu produk. Positioning seringkali digunakan untuk mengartikan atau menggambarkan image suatu produk dibandingkan dengan produkproduk pesaingnya.

Positioning berhubungan dengan bagaimana konsumen menempatkan produk dalam otaknya, di dalam alam khayalnya, sehingga calon konsumen memiliki penilaian tertentu dan mengidentifikasikan dirinya dengan produk tersebut. Positioning merupakan strategi yang berusaha menciptakan perbedaan yang unik dalam benak konsumen sasaran, sehingga terbentuk citra (image) produk yang lebih unggul dibandingkan dengan produk pesaing.

Dalam pariwisata, Menurut Ries and Trout dalam Rosalina (2007) positioning bukan mengenai apa yang dilakukan terhadap produk pariwisata tetapi apa yang dilakukan untuk menumbuhkan persepsi dan menanamkannya di benak wisatawan. Positioning bertujuan membantu wisatawan sebagai konsumen mengetahui perbedaan sebenarnya antara suatu destinasi wisata yang 
satu dengan destinasi wisata pesaing (Yoeti, 2003).

\section{Brand sebagai Wujud Citra Destinasi}

Brand merupakan perwujudan nyata dari citra destinasi tersebut. Brand merupakan identitas dari suatu destinasi pariwisata, sehingga brand yang baik adalah brand yang didalamnya mengandung nilai rasional maupun emosional. Agar brand tersebut prestisius maka brand tersebut harus memiliki ekuitas (brand equity) yang tinggi. Semakin tinggi ekuitas brand tersebut maka akan semakin banyak konsumen yang akan mengkonsumsi/memilih produk yang memiliki brand tersebut.

\section{METODE PENELITIAN}

\section{Pendekatan Penelitian}

Penelitian ini merupakan perpaduan metode kualitatif dan kuantitatif. Metode kuantitatif dipakai untuk mengukur secara matematis instrumen-instrumen skalatis seperti dalam analisis data secara statistik deskriptif khususnya data yang berupa angka atau nominal. Sedangkan metode analisis kualitatif digunakan untuk mempertajam analisis kuantitatif

\section{Pengumpulan Data}

Teknik pengumpulan data dilakukan berdasarkan dua jenis, yaitu data primer dan data sekunder. Pengumpulan data primer dengan penyebaran kuesioner kepada wisatawan di Kawasan Kotagede. Data sekunder adalah data yang diperoleh dari instansi dan literatur.

\section{Analisis Data}

Analisis data dilakukan secara kualitatif dan kuantitatif. Analisis dengan skoring digunakan untuk mengetahui penilaian responden terhadap kualitas produk wisata. Dalam penelitian ini, skala Likert digunakan untuk menilai tingkat kualitas produk wisata di Kotagede sesuai dengan indikator unsur-unsur produk wisata. Analisis deskriptif presentase digunakan untuk mendeskripsikan persepsi terhadap keunikan produk wisata dan karakteristik Kotagede untuk mencari positioning Kotagede. Untuk menganalisa data penelitian yang bersifat kualitatif yang didapat dari in-depth interview digunakan analisa wacana. Analisis ini digunakan untuk melengkapi dan menutupi kelemahan dari analisa kuantitatif yang telah dilakukan sebelumnya.

\section{HASIL PENELITIAN DAN \\ PEMBAHASAN}

\section{Kotagede sebagai Destinasi Wisata}

Wisata Kotagede merupakan rangkaian dari wisata Kraton Yogyakarta. Kotagede sebagai suatu kawasan wisata memiliki kelengkapan komponen dari industri pariwisata. Kotagede dikembangkan menjadi destinasi wisata karena memiliki beberapa tempat bersejarah yang berfungsi sebagai objek wisata.

1. Pasar Kotagede. Pasar Kotagede berdiri sejak abad 6M. Didirikan pada masa pemerintahan $\mathrm{Ki}$ Ageng Pamanahan. Pasar ini buka setiap hari, tetapi puncak keramaiannya adalah pada hari pasaran legi.

2. Kompleks Masjid Agung dan Makam Raja Kotagede. Kompleks Masjid Agung Kotagede terletak di Kelurahan Jagalan. Kompleks ini meliputi masjid, makam/pasareyan Hastana Kitha Ageng, serta sendang seliran. Masjid Agung Kotagede sendiri masih dipakai untuk kegiatan sholat 5 waktu, sedangkan untuk kompleks makam dan pemandian dijadikan sebagai objek wisata. Para wisatawan dapat melihat ke dalam makam pada hari-hari tertentu dengan menggunakan busana khusus yang disediakan yaitu berupa busana surjan lurik dan blangkon untuk pria dan kemben untuk wanita. 
3. Omah Loring Pasar. Dulunya tempat ini merupakan tempat tinggal Dhanang Sutawijaya sehingga dia disebut juga Raden Ngabehi Loring Pasar. Tempat ini merupakan salah satu rumah berarsitektur Jawa yang lengkap.

4. Gang Rukunan. Dikenal juga dengan istilah between two gates. Jalan ini sebetulnya ruang milik pribadi namun dijadikan jalan umum dengan kerelaan pemiliknya

5. Langgar Dhuwur Boharen. Langgar dhuwur adalah langgar yang berada di loteng beberapa rumah tradisional Jawa di Kotagede

6. Pasareyan Hastarengga. Pasareyan (makam) Hastarengga dibangun atas gagasan Sri Sultan Hamengku Buwono VIII untuk kompleks makam keluarga dan keturunannya.

7. Situs Cepuri dan Baluwarti. Merupakan situs sisa-sisa/reruntuhan benteng dalam dan luar yang dahulu mengelilingi kawasan kerajaan Mataram Islam.

8. Watu Gilang, Watu Gatheng, dan Watu Genthong. Watu Gilang yang dipercaya orang sebagai tahta raja-raja MataramIslam berupa papan batu berwarna hitam legam. Pada sisi atas batu itu terdapat prasasti dalam berbagai bahasa. Sedangkan Watu Gatheng berupa tiga batu bulat masif menyerupai bola yang berwarna kekuning-kuningan. Menurut legenda, ketiga "bola" batu tersebut adalah alat permainan Pangeran Rangga, salah seorang putera Panembahan Senopati. Namun ada juga yang berpendapat bahwa batu-batu tersebut adalah peluru meriam kuno.

9. Pengrajin perak. Pengrajin perak merupakan daya tarik utama dari Kotagede. Selain pengrajin individu, di
Kotagede juga terdapat toko-toko besar yang menjual perak.

10. Kipo dan Kembang Waru. Kipo dan Kembang Waru merupakan salah satu makanan tradisional khas Kotagede

11. Heritage Trail. Paket heritage trail diadakan oleh sebuah kelompok masyarakat di Kotagede. Paket heritage trail menawarkan tiga macam paket, yaitu: wisata lorong, wisata arsitektur, dan wisata spiritual.

12. Upacara Nawu Sendhang. Upacara Nawu Sendang merupakan upacara menguras sendang atau membersihkan sendang. yang berada di Kompleks Makam Raja-Raja Mataram dan Mesjid Agung Kotagede.

\section{Positioning Kotagede}

Positioning Kotagede dicari dengan menggunakan dua variabel, yaitu dari sisi segmentasi pasar dan sisi produk wisata

1. Segmentasi Pasar. Berdasarkan data profil wisatawan yang didapat, maka wisatawan yang datang ke Kawasan Kotagede mayoritas adalah usia muda (21-30 tahun) dengan tingkat pendidikan sarjana (S1) dan mayoritas adalah pelajar/mahasiswa. Sehingga dapat disimpulkan bahwa wisatawan yang berkunjung ke Kotagede adalah dari golongan muda.

2. Keunikan. Berdasarkan temuan penelitian maka keunikan Kotagede terletak pada keberadaan rumah-rumah joglonya.

3. Kualitas Produk Wisata. Penilaian kualitas produk wisata meliputi 3 (tiga) hal, yaitu: atraksi, amentias akomodasi, dan aksesibilitas.

Tabel 1. Kualitas Produk Wisata Kotagede

\begin{tabular}{|c|l|c|}
\hline No & \multicolumn{1}{|c|}{ Produk Wisata } & Skor \\
\hline 1 & Keberagaman Atraksi & 3,11 \\
\hline
\end{tabular}




\begin{tabular}{|c|l|c|}
\hline No & \multicolumn{1}{|c|}{ Produk Wisata } & Skor \\
\hline 2 & Amenitas - akomodasi & 2,58 \\
\hline 3 & Aksesibilitas & 2,81 \\
\hline
\end{tabular}

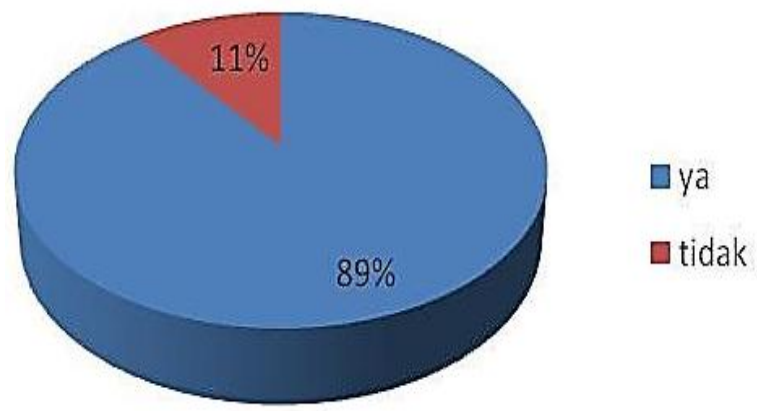

Gambar 3. Keinginan untuk Melakukan Kunjungan Ulang

Berdasarkan tabel diatas, indikator atraksi memperoleh skor tertinggi, sehingga keberagaman atraksi menjadi keunggulan dari Kotagede. Demikian juga analisis segmen, keunggulan, dan keunikan maka positioning Kawasan Kotagede sebagai destinasi pariwisata adalah: kalangan muda, atraksi, dan joglo

\section{Ekuitas Kotagede}

Konsep Costumer-Based Brand Equity dari Keller (2003) yang meliputibrand salience, brand imagery, brand judgments and feelings, dan brandresonance digunakan untuk merumuskan ekuitas yang kuat bagi brand Kotagede.

\section{Brand Saliance}

Joglo merupakan top-of-mind wisatawan apabila mendengar kata 'kotagede'. Wisata sejarah dan bersenang-senang menjadi hal yang paling ingin dilakukan oleh wisatawan ketika berkunjung ke Kotagede. Makam Raja dan Masjid Kotagede menjadi tempat yang ingin didatangi ketika berkunjung ke Kotagede.

\section{Brand imagery}

Wisatawan berpendapat bahwa joglo merupakan hal yang paling sesuai untuk menjadi ikon Kotagede.

\section{Brand judgments and feelings}

Kualitas produk wisata di Kotagede dinilai berdasarkan tiga aspek besar yaitu atraksi, amenitas - akomodasi, dan aksesibilitas. Secara keseluruhan kualitas produk wisata di Kotagede masih belum memuaskan, namun untuk atraksinya dinilai sudah cukup beragam.

\section{Brand resonance}

Lebih dari $80 \%$ responden merupakan repeater (berkunjung lebih dari satu kali) dan $89 \%$ menyatakan akan melakukan kunjungan ulang.

Wisatawan beranggapan bahwa keberagaman atraksi di Kotagede membuat mereka ingin melakukan kunjungan ulang ke Kotagede. Oleh karena itu positioning dan unsur-unsur yang dapat dijadikan citra (image) Kawasan Kotagede adalah sebagai berikut:

\section{Tabel 2. Positioning dan Unsur-Unsur Citra Kotagede}

\begin{tabular}{|c|c|}
\hline & Keterangan \\
\hline Positioning & $\begin{array}{l}\text { Wisatawan muda, joglo, dan } \\
\text { keberagaman atraksi }\end{array}$ \\
\hline Ekuitas & $\begin{array}{l}\text { 'Kompleks makam dan masjid', } \\
\text { joglo, wisata sejarah merupakan } \\
\text { nilai lebih bagi Kawasan Kotagede } \\
\text { Joglo dapat dijadikan sebagai ikon } \\
\text { Kotagede } \\
\text { Keberagaman atraksi meupakan } \\
\text { hal yang layak dipertimbangkan } \\
\text { oleh wisatawan apabila hendak } \\
\text { memutuskan berkunjung ke } \\
\text { Kotagede wata } \\
\text { Loyalitas wisatawan pada } \\
\text { Kotagede dikarenakan keberaga- } \\
\text { man atraksinya. }\end{array}$ \\
\hline
\end{tabular}

\section{KESIMPULAN DAN REKOMENDASI Kesimpulan}

Wisatawan domestik berpendapat citra Kotagede sebagai destinasi pariwisata adalah joglo, keberagaman atraksi, dan merupakan 
destinasi yang sesuai/cocok untuk kalangan muda.

\section{Rekomendasi}

1. Pelestarian rumah-rumah Joglo di kawasan Kotagede, Ancaman mulai hilangnya rumah-rumah Joglo di kawasan Kotagede harus mulai diantisipasi. Kegiatan-kegiatan antisipasi dapat berupa penyuluhan/edukasi tentang pentingnya mempertahankan rumah Joglo hingga mengajak kerja sama berbagai pihak terutama dalam hal bantuan pendanaan bagi masyarakat yang memiliki rumah Joglo dalam nal pengelolaannya.

2. Pengembangan atraksi yang lebih bersifat wisata sejarah dan membidik segmen pasar anak muda. Pengembangan atraksi tidak hanya pada atraksi utama tetapi juga atraksi-atraksi pendukungnya.

3. Pengembangan fasilitas pendukung seperti pedestrian, toilet umum, dan rute wisata Kawasan Kotagede.

\section{DAFTAR PUSTAKA}

Andreassen, Tor Walin, Lindestad, Bodil .1998 "Customer loyalty and complex services: The impact of corporate image on quality, customer satisfaction and loyalty for customers with varying degrees of service expertise", International Journal of Service Industry Management, Vol. 9 Issue: $\quad 1, \quad$ pp.723, https://doi.org/10.1108/09564239 810199923

Cooper, Flecher et.al 1998. Tourism Principle and Practice. Third edition, Pearson Education Limited, Edinburgh Gate, Harlow, England

Echtner, Charlotte M.and Ritchie, J.R Brent. 2003 "The Meaning and
Measurement of Destination Image". The Journal of Tourism Studies Vol. 14(1) pp 37-48

LeBlanc, Gaston and Nguyen, Nha. 1996. "Cues Used by Customers Evaluating Corporate Image in Service Firms". International Journal of Service Industry Management, Vol 7, No. 2, pp. 44-56.

Pearce, P.L. 1988. The Ulysses Factor. New York: Springer-Verlag

Rosalina, Bayu. 2007. "Persepsi Pelaku Pariwisata terhadap Brand Positioning Daerah Istimewa Yogyakarta". Tesis tidak diterbitkan. Universitas Gajah Mada: Sekolah Pasca Sarjana

Yoeti, Oka A. 2003. Tours and Travel Marketing, Cetakan Pertama, Jakarta: PT.Pradnya Paramita

(http://ensiklo.com/2014/09/kotagede-suduttenggara-kota-yogyakarta-yangterkenal-dengan-kerajinan-perak/). http://www.pelita.or.id/baca.php?id=47101 